\title{
Runaway behavior among children in residential care in St. Petersburg: A qualitative study
}

\author{
Ksenia Yu. Eritsyan, Olga I. Kolpakova \\ Sociological Institute of FCTAS RAS, Saint Petersburg, Russia \\ *Corresponding author. E-mail: ksenia.eritsyan@gmail.com
}

Background. Runaway behavior among children in residential care is a serious social problem in all countries of the world. Existing scientific data on risk factors and motives of runaway from out-of-home care may not be absolutely relevant to the Russian cultural context.

Objective. To describe risk factors and the motives that cause children to runaway from residential care.

Design. A qualitative study that included 2 focus groups with staff and graduates of residential care supplemented by the analysis of 23 cases of child runaways from residential care in St. Petersburg.

Results. The study revealed the following runaway risk factors and motives: 1) running to parents or relatives, 2) romantic and/or sexual relations, 3) interaction with peers, 4) psychiatric problems, 5) addictive behavior, 6) avoidance of conflicts, 7) physical or emotional violence, 8) unmotivated runaways for entertainment, 9) problems adapting to the care institution, 10) dissatisfaction with the conditions at the care institution. Moreover, in this study, two different types of runaways have been identified, including relatively "true" runaways and those who are not psychologically experienced as such, but are only disobeying the formal rules of the care institution.

Conclusions. Runaways of children from residential care are extremely heterogeneous in nature. In further empirical studies, it should be taken into account that runaways may be true and formal. There can be multiple reasons for running away: the care institution itself, a child's personality, or his or her social network outside of the care institution.

Keywords: runaway, residential care, children, orphanage, focus group, motives

\section{Introduction}

Runaway behavior among children in residential care is a serious social problem all around the world. Estimating the prevalence of this phenomenon is a complex methodological task, since not every runaway case is properly registered. 
A considerable amount of data has been accumulated on runaways who were raised in families (Tucker, Edelen, Ellickson, \& Klein, 2011; Pergamit, 2010). Prevention of runaway behavior is important for two main reasons. First, in most cases, the act of running away signifies that the child is in trouble. Second, research shows that running away can lead to significant negative consequences for the children themselves and their social network (Kim, Tajima, Herrenkohl, \& Huang, 2009). The runaway is exposed to a risk of criminal victimization, sexual abuse, and negative health consequences (Lin, 2012). Besides that, international longitudinal studies show that the negative effects of running away can be long term. Thus, children who run away are more likely to drop out of school, get involved in delinquent behavior (including prostitution), and become illegal drug users. In adulthood, these children are also much more likely to suffer from depression. Girls who runaway got involved in sexual relationships 1.7 times more often than their peers within one year after running away (Tucker et al., 2011; Lin, 2012). And the longer children stay out of the home, the greater the risk of various negative consequences occurring (Lin, 2012).

There is much less scientifically substantiated data available on the absconding of children brought up outside of the family. That is probably because different countries provide different types of social care for children without parental care, such as foster families, orphanages, boarding schools, and other types of residential care. Patterns obtained from the studies of foster-family runaways (for example, Crosland, Dunlap, 2015; Karam \& Robert, 2013; Lin, 2012;) do not always apply to absconding from orphanages and boarding schools, a common type of residentialcare in the Russian Federation.

Despite the fact that $83 \%$ of orphans are currently living with families, it is still necessary for some orphans to be put under the supervision of care institutions of various departmental affiliations. A little less than 1,500 such institutions function in the territory of the Russian Federation. Depending on a child's age and health, an orphan or a child left without parental care is enrolled into one of these institutions. From birth and up to three or four years of age, orphans not living with families live in a medical institution called a children's home, or, if the child has health problems, in a specialized children's home. Children aged 4-18 live in an orphanage or a boarding school for orphans and children left without parental care. If the child has health problems, he or she is sent to similar institutions of a special (correctional) type. In the social-protection system, there are also shelters and social and rehabilitation centers for minors, but these are considered a temporary residence for children in difficult life situations. While children are staying in these institutions, their family situation could either improve, and, in that case, they are returned to their parents, or it could get worse, and, in that case, their parents are deprived of their parental rights and the children are transferred to the orphanage or boarding school.

In general, children in residential care are much more likely to abscond than children living with a family. This is no surprise, given the fact that such institutions mainly host children who have faced various social problems (Attar-Schwartz, 2012). A recent systematic review of out-of-home runaway studies (including data on foster family runaways) (Bowden, Lambie, 2015) showed the presence of factors that allow researchers to predict a higher risk of runaway behavior in children from 
such institutions, which are systematically identified in empirical studies. At the individual level, these factors are: female gender, older age, nontitle nationality, substance use, behavioral difficulties, and/or a prior history of absconding. Family ties have a lot of influence, as do relationships with peers. The institution itself plays a great role in the prevention of runaways by filling the lives of children with joy and interest, providing more extensive supervision, and establishing regulations. Moving children between institutions is another important factor; those children who changed several host families or institutions during their lives lack time to form a strong connection with any one home and, accordingly, are subject to a higher risk of running away. Moreover, each runaway enhances their reputation as "difficult" children, so the caretakers start to perceive them as unmanageable, which increases the risk (Lin, 2012).

The above patterns can be determined by culture to a large extent and can manifest themselves differently in the cultural context of Russia. To date, only a small number of empirical studies on runaways have been published, and a majority of them describe runaways from families (Kolodina, 2014) or they do not specify where the runaway children came from (Breeva, 2004; Kiseleva 2013; Sheremetyev, \& Vedyashkin, 2012). Studies about residential care are more rare (Albova, Troitskaya, \& Shumilina, 2016) and may not focus specifically on the runaway problem, although they do mention it (Astoyants, 2006).

\section{Method}

The purpose of this study is to clarify the phenomenology of running away from out-of-home care, namely risk factors and motives for children absconding from residential care in St. Petersburg, Russia. In accordance with the purpose of the study, qualitative methods were predominantly used. In St. Petersburg, two focus groups with key informants were conducted:

1. The first focus group was composed of stakeholders working with children in residential care regarding the causes and conditions of children running away from these institutions. In total, 10 experts were involved in the focus group: two representatives of social protection institutions from different districts of the city, two representatives of district Commissions for the Affairs of Minors and Protection of Their Rights, four representatives of orphanages and boarding schools, one law enforcement representative, and one representative of the youth volunteer movement.

2. The second focus group was composed of graduates of residential care, regarding the reasons and conditions for the running away of children from such institutions. In total, 8 graduates of residential-care institutions for children, 5 girls and 3 boys, were involved in the focus group (Table 1).

Additionally, a case study method was used to analyze cases of children running away from residential care in St. Petersburg. A total of 23 runaway cases were analyzed, including 15 cases recorded by one of the orphanages in St. Petersburg and 7 cases recorded by the Juvenile Affairs Division in one of St. Petersburg districts. Runaways were documented in a specially designed form, filled out on the basis of personal records and interviews with a case supervisor. 
Table 1. Participants of the focus group with graduates of residential care

\begin{tabular}{cccc}
\hline$\#$ & Gender & Age & Placement experience \\
\hline 1 & Male & 29 & Urban; specialized for children with special needs \\
2 & Male & 18 & Urban \\
3 & Female & 17 & Suburban \\
4 & Female & 17 & Suburban \\
5 & Female & 18 & Urban outside St. Petersburg \\
6 & Female & 19 & Urban \\
7 & Female & 18 & Urban \\
9 & Male & 19 & \\
\hline
\end{tabular}

\section{Results}

Participants of the focus groups (hereinafter referred to as experts) note that cases of minors running away from residential care are quite heterogeneous in nature: children may not want to live in an institution (any or specific one) and are determined to leave it, or running away is only formal. Such "formal" cases include: 1) returning later than agreed to the institution and 2) planned runaway from the institution to parents or relatives for a certain period, when parents or relatives cannot provide the institution's staff with any necessary documents from guardianship and trusteeship authorities. In such cases, children can warn caretakers about their intention and fill in the necessary papers; however, without any proper coordination with guardianship and trusteeship agencies, these cases can formally be regarded as unauthorized leave.

Based on the data obtained in the study, the main risk factors and motives for running away from residential care can be characterized as follows.

1. Going to parents or relatives

Of the 23 cases analyzed, 8 were cases of this type. At present, a significant proportion of children in residential care are social orphans. Children know their parents, stay in contact with them in person or by phone, and often live next to them. Running away to parents can be motivated by a longing for home and care and concern for relatives, including the need to help the family with housework. There are a few cases where children go looking for their parents, for example, knowing that he/she has been released from prison.

2. Runaway in connection with romantic and sexual relationships

Among all the cases analyzed within the study, at least three belong to this type. In general, older children, mainly girls, are more inclined to run away for such a reason. In one analyzed case, there was a homosexual teenage boy. Here we can find runaways connected with both casual relationships andcohabitation. Quite common are cases of cohabitation of underage girls with adult men, and such cases are rarely taken to court, since girls tend to alter their testimony. 
Experts believe that these runaways are difficult to prevent, especially when children enter an orphanage residential-care institution while already being in a relationship or having such an experience. For orphans and children left without parental care, sexual and romantic relationships can be a kind of substitute for the love they did not receive in the family.

3. Runaways related to interaction with peers

Such cases are about communication with children and adolescents outside the institution, especially when such children do not have any clear limits on the time of return to the residential-care institution. This may include short-term runaways to specific external events and parties.

4. Runaways related to psychiatric problems

Experts claim that children with certain psychiatric disorders have special needs in terms of their educational environment and medical care, which residential-care institutions are often not able to fulfill. Such children cannot cope with the daily routine and find it difficult to connect with other minors. The staff also lack sufficient skills and resources to effectively communicate with such children. It is not uncommon for children to be moved to residential-care institutions directly from psychiatric hospitals. In this case, the existing psychiatric problems can be aggravated by the difficulties of adaptation to the institutional environment.

\section{Addictive behavior}

Children with alcohol and drug dependency are likely to run away frequently. Just like in the case of psychiatric problems, the staff of a residential-care institution may not have sufficient skills and resources to cope with such behavior.

6. Runaway in attempt to avoid conflicts

Experts say such cases are frequent. Quite often, after a theft of property has occurred, a runaway is prompted by the fear of punishment from peers and/or caretakers.

7. Runaway as a result of physical or emotional violence

Among the analyzed cases, none of this type were encountered. Nevertheless, experts and graduates of residential care said that such cases may take place. Violence in an institution may be caused by hazing or bullying on the part of older children. Also, according to the testimonies of graduates of residential care, in some cases, such manifestations of hazing can be provoked or encouraged by caretakers:

Violence in orphanages doesn't come from caretakers, but from older children. That is, the caretaker approached the eldest and asked to help her. Then she left, closing the door, as if she did not see anything. That's how it happens (graduate of the residential-care institution, \#2, male, 18 years old).

Extremely traumatic for the graduates of residential care can be their experience of psychological violence on the part of caretakers:

- Caretakers insulted, humiliated us in any possible way. They used to say that our mothers were whores, who gave birth to us, but did not bother to bring us up. They said we are 
useless and should be interned and sent to a psychiatric hospital (graduateof the residential-care institution, \#7, female, 18 years old).

- How kind of them.

- Our caretakers were good.

- Same with us.

(Graduates of residential-care institutions).

It should be noted that the prevalence and influence of this factor obviously varies greatly depending on the institution of residential care.

8. Unmotivated runaway for the purpose of entertainment

Runaways from residential-care institutions often do not have clear motivation and happen despite the background of child's general satisfaction with the institutional environment. Moreover, often children themselves cannot explain their reasons for running away:

Everything was fine in my orphanage. My case is different. I ran away because I was curious what they are doing there when they run away. I ran because I wanted to see where and how they live, what they eat. Well, yes, I slept in the basement, on the pipes, on a mattress. I intended to spend a week out there. One day is not enough to see everything. A car used to come with bread; we helped unload it. They gave us a loaf; that was great! We ran away together: two people, and I was the third. Well, I have seen what I wanted to see (graduate of the residential-care institution \#1, male, 29 years old).

9. Runaway associated with adaptation period to a residential-care institution

Experts highlighted the highest prevalence of runaways among children in the first year of their stay in a residential-care institution. Quite often, children who were separated from their parents at a later age tend to run away. This is confirmed by graduates of residential-care institutions:

Imagine, a child lived in the family from the early childhood, and suddenly his parents decided to send him to an orphanage. And he runs away because the orphanage is alien to him, he is used to living in a family. Moreover, he has a lot of friends there, where he lived with his parents, and that's why he runs away. (Graduate of the residential-care institution \# 1, male, 29 years old).

Runaway behaviors are extremely common among children who are often moved from one residential-care institution to another. These children do not have time to adapt to the ever-changing rules and develop runaway behavior patterns to cope with stress. On the other hand, quite often runaways formed a connection with another residential-care institution and the children there. When separated from their main social connections, these children leave to meet their friends from the former place:

- And often those who move continuously from one orphanage to another, run away. Some can change five orphanages in a row.

- I changed several orphanages because of problems with my eyesight. I was moved from one orphanage to another. Now it's fine-I have been cured. But in my childhood I was thrown around. You start to get used to an orphanage, and ...

(graduate of residential-care institution \#3, female, 17 years old). 
Runaway behavior can also be associated with transitional adaptation from one type of institution to another, for example, from a close- to an open-type institution. Less strict rules, the possibility to spend time on their own outside the institution, sometimes, pocket money (for example, scholarships)-all this is completely new and unusual for a minor.

In such cases, running away can be part of a normal adaptation process to such new living conditions.

In other cases, on the contrary, adolescents can expect more from a new social role, for example, that of a student. They expect even greater freedom than they used to have and are psychologically unprepared to follow the rigid rules.

10. Runaways associated with dissatisfaction with the living conditions in the residential-care institution

Experts consider it a difficult case when a child is enrolled in a residential-care institution with a considerable prior experience of independent and/or antisocial life, for example, several years of cohabitation, including the experience of maternity/paternity, self-reliant separate living, or street and criminal history. In this case, according to experts, it may take a very long time for such a child to adapt to life in the residential-care institution, with the need to study, strict hierarchy and rules, daily routine, etc. Depending on the child's personality, he or she may never get used to it. According to experts, for such minors, it might be more appropriate to develop a different type of care institution.

In other cases, runaway behavior can be developed on the basis of children's discontent with individual requirements, including the daily routine, study requirements, limited choice of profession, etc.:

We were killing time, and it was going well on weekends, but anyway, from Monday to Friday all days were the same; we couldn't cook anything special or go anywhere. Anyway, from Monday to Friday-it's very boring, although there are workshops and clubs. But people are different. Maybe a certain workshop is good for me now, but for another person

... (obscene language)-it's of no interest. Maybe you want to go for a walk, but you can do it at a certain time only, otherwise you will not be allowed. Well, that's it (graduate of the residential-care institution \#6, female, 19 years old).

In general, experts note that among other factors, a positive climate in the care institution and common goals and hobbies will help prevent minors from running away from residential-care institutions.

\section{Discussion}

In a broad sense, we may distinguish several types of runaways: those at the level of the institution (usually this is something the child runs away from), at the level of the child's personality, or at the level of his/her social network external to the institution (something the child looks for when he or she runs away). This partly corresponds to the empirical classifications of Zide and Cherry (1992) and Biehal and Wade (2000), which mainly distinguish between two types of runaways a) where children seek something outside the system-the authors mostly describe the ones motivated by adventure; and b) where children run from some ill-being. 
Our empirical classification adds a third dimension-a child's personal characteristics, which may cause poor adaptation within the institutional system and shows that, at least in our study, seeking something outside the system is mostly connected to the importance of social contacts. Both these additions correspond well to the findings of Finnish researchers (Hoikkala \&Kemppainen, 2015). In other studies, we haven't found the distinction between true runaways and unauthorized leaves, which happen mostly due to formal reasons but might not be attributed to a serious motivation to leave the institution. This finding might be culturally specific and/or overlooked in previous studies.

\section{Conclusion}

As this study has shown, runaways of children from residential care are extremely heterogeneous in nature. Running away can be a turning point in a child's life, perceived as such by the child and caretakers, or it may be one of the routine behavioral patterns of no importance either to the child or caretakers. In our opinion, such a division has important methodological applications and should be taken into account when conducting empirical studies on runaways, especially quantitative studies. Perhaps, it is the underestimation of the objective and subjective significance of the event (conditionally true runaways vs. formal violation of the rules related to imperfect legislation) that may, among other factors, describe the origin of contradictory patterns found in different empirical studies.

However, this preliminary descriptive study has important policy implications. There are institutional-level measures that might effectively prevent runaways among all children. Those include prevention of physical and emotional violence among children and between children and caregivers, the presence of an effective conflict-management system, taking children's views on ways to improve living conditions into account, the avoidance of the unnecessary transfer of children from one organization to another, and the prevention of runaways while children adapt to a new institution. A different set of measures needs to be developed to ensure the adaptation of children with special needs to the institutional-care system, including children with behavioral and psychiatric problems and addictive behavior. Finally, the third direction of efforts might be focused on the need to deal with the social connections of the children with people outside the care facilities, including family, friends, and romantic partners.

\section{Limitations}

The study has several limitations for the possible generalization of the results obtained. First of all, it's the geographic scope of the study-the city of St. Petersburg, the second largest metropolis in Russia. Second, the institutions covered in the study; perhaps incorporating a wider range of institutions would reveal risk factors and motives of runaway behavior other than those identified in this study. Also, since the focus group was conducted with young people who are no longer in residential-care institutions, we assume that some new phenomena could have slipped through the net, and some of the phenomena described by the participants, on the contrary, may be somewhat obsolete. At the same time, this approach, in 
our opinion, made it possible for young people to speak more openly about their experience.

In general, to the best of our knowledge, this is one of the first published qualitative studies on this issue in Russia, and we hope that these data will be used to further develop large-scale quantitative studies on this topical problem.

\section{Acknowledgments}

This study was supported by a grant from the Russian Science Foundation (project no. 16-18-10372) "Children's social trajectories in contemporary Russia".

\section{References}

Albova, E.A., Troitskaya, I.V., \& Shumilina, E.M. (2016). Strategija profilaktiki pobegov v uslovijah socialnogo prijuta dlja detej [Strategy of prevention of shoots in conditions of a social shelter for children]. Ulyanovsk, Russia: Publishing house "Zebra".

Astoyants, M.S. (2006). Deti-siroty: analiz zhiznennyh praktik v uslovijah internatnogo uchrezhdenija. [Orphans: An analysis of life practices in a residential institution. Experience of participant observation]. Sociologicheskie issledovanija [Sociological Research], 3, 54-63.

Attar-Schwartz, S. (2013). Runaway behavior among adolescents in residential care: The role of personal characteristics, victimization experiences while in care, social climate, and institutional factors. Children and Youth Services Review, 35(2), 258-267. doi: 10.1016/j.childyouth.2012.11.005

Biehal, N. \& Wade, J. (2000). Going missing from residential and foster care: Linking biographies and contexts. British Journal of Social Work, 30(2), 211-225. doi: 10.1093/bjsw/30.2.211.

Bowden, F., \& Lambie, I. (2015). What makes youth run or stay? A review of the literature on absconding. Aggression and Violent Behavior, 25, 266-279. doi: 10.1016/j.avb.2015.09.005 Breeva, E.B .(2004). Socialnoe sirotstvo. Opyt sociologicheskogo obsledovanija. [Social orphanhood. Experience of sociological survey]. Sociologicheskie issledovanija [Sociological Research], 4, 44-50.

Crosland, K., \& Dunlap, G. (2015). Running away from foster care: What do we know and what do we do? Journal of Child and Family Studies, 24(6), 1697-1706. doi: 10.1007/s10826-0149972-x

Hoikkala, S., \& Kemppainen, M. (2015). Running away from children's residential care: The finnish case. International Journal of Child, Youth and Family Studies, 6(3), 466-477. doi: $10.18357 /$ ijcyfs.63201513566

Karam, R., \& Robert, M. (2013). Understanding runaway behaviour in group homes: What are runaways trying to tell us? Journal of Community Positive Practices, 13(2), 69.

Kim, M. J., Tajima, E. A., Herrenkohl, T. I., \& Huang, B. (2009). Early child maltreatment, runaway youths, and risk of delinquency and victimization in adolescence: A mediational model. Social Work Research, 33(1), 19-28. doi: 10.1093/swr/33.1.19

Kiseleva, T.G. (2013). Diagnostika prichin samovolnyh uhodov detej iz semej i uchrezhdenij $s$ kruglosutochnym prebyvaniem [Diagnosis of the reasons for unauthorized leaving of children from families and institutions with a 24-hour stay]. Vestnik Cheljabinskogo gosudarstvennogo universitet [Bulletin of the Chelyabinsk State University], 34 (325). Series Obrazovanie i zdravoohranenie [Education and health care]. Vol. 2, 116-120.

Kolodina, A.V. (2014). Psihologicheskij portret podrostka, sovershajushhego samovolnye uhody iz doma [Psychological portrait of a teenager making unauthorized departures from home]. 
Vestnik Omskogo universiteta. Serija "Psihologija" [Bulletin of Omsk University. Series "Psychology"], 1, 32-42.

Lin, C.H. (2012). Children who run away from foster care: Who are the children and what are the risk factors? Children and Youth Services Review, 34(4), 807-813. doi: 10.1016/j.childyouth.2012.01.009

Pergamit, M.R. (2010). On the lifetime prevalence of running away from home. Urban Institute (NJ1). Retrieved from https://eric.ed.gov/?id=ED510506

Tucker, J.S., Edelen, M.O., Ellickson, P.L., \& Klein, D.J. (2011). Running away from home: A longitudinal study of adolescent risk factors and young adult outcomes. Journal of Youth and Adolescence, 40(5), 507-518. doi: 10.1007/s10964-010-9571-0

Sheremetyev, I.I., \& Vedyashkin, V.N. (2012). Brodjazhnichestvo u podrostkov, oslozhnennoe delinkventnym povedeniem [Adolescent vagrancy complicated by delinquent behaviours]. Socialnaja i klinicheskaja psihiatrija [Social and Clinical Psychiatry], 22(3), 89-91.

Zide, M., \& Cherry, A. (1992). A typology of runaway youths: An empirically based definition. Child and Adolescent Social Work Journal, 9, 155-168. doi: 10.1007/BF00755230

Original manuscript received June 05, 2017 Revised manuscript accepted october 04, 2017 First published online November 30, 2017 